\title{
The use of products from ground-based GNSS observations in meteorological nowcasting
}

\author{
E. Terradellas and B. Téllez \\ Agencia Estatal de Meteorología, Barcelona, Spain \\ Received: 17 February 2010 - Revised: 18 March 2010 - Accepted: 19 April 2010 - Published: 22 July 2010
}

\begin{abstract}
Convective rainfall is often focalized in areas of moisture convergence. A close relationship between precipitation and fast variations of vertically-integrated water vapour (IWV) has been found in numerous cases. Therefore, continuous monitoring of atmospheric humidity and its spatial distribution is crucial to the operational forecaster for a proper nowcasting of heavy rainfall events.

The microwave signals continuously broadcasted by the Global Navigation Satellite Systems (GNSS) satellites are influenced by the water vapour as they travel through the atmosphere. Estimates of IWV retrieved from ground-based GNSS observations may, then, constitute a source of information on the horizontal distribution and the time evolution of atmospheric humidity. At the Spanish Meteorological Agency (AEMET), a near-real-time map of IWV estimates retrieved from ground GNSS measurements in the Iberian Peninsula and West Mediterranean region is operationally built and presented to the forecaster. The maps are generated every 15 minutes following a one-dimensional variational assimilation scheme with the previous map as the background state.

A case study is presented in order to illustrate some strengths and weaknesses of the product, to assess the potential benefit of using GNSS products in nowcasting and to define the steps to be done in order to make use of the full potential of the method.
\end{abstract}

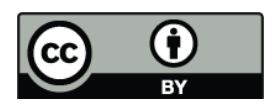

Correspondence to: E. Terradellas (eterradellasj@aemet.es)

\section{Introduction}

In spite of being a minor component of the Earth's atmosphere, water plays a fundamental role in a variety of atmospheric processes of a wide range of scales. Information on the spatial distribution and time variations of water vapour concentration is of crucial importance to weather forecasting and climate monitoring and research. Nevertheless, humidity is one of the most poorly characterized meteorological parameters. Radiosonde releases yield measurements of atmospheric humidity (among other parameters), but they are very sparse and present a limited time resolution of 12 to $24 \mathrm{~h}$. Surface-based radiometers are capable of measuring the column-integrated water vapour (IWV) with a high temporal resolution, but they are costly, require frequent calibration and reliability is affected by the weather conditions, especially by rain (Rocken et al., 1995). Several polar-orbiting satellites carry multichannel radiometers designed for humidity sensing with planetary-scale coverage. Nevertheless, infrared sensors present a limited performance in cloudy regions and retrievals from microwave sensors are not very reliable over land (Melsheimer and Heygster, 2008).

The microwave signals continuously broadcasted by the Global Navigation Satellite Systems (GNSS) are slowed when they pass through the Earth's atmosphere, where the speed of light is lower than in a vacuum. The delay is produced both in the ionosphere and in the lower electricallyneutral atmosphere. The ionospheric delay is dispersive and, therefore, can be determined and removed by using dualfrequency receivers (Spilker, 1980; Brunner and Gu, 1991). On the other hand, the delays originated in the neutral atmosphere depend on its constituents. Using the method described in Bevis et al. $(1992,1994)$, the delay caused by water vapour can be estimated and used to retrieve the IWV. The quality of IWV data retrieved from GNSS observations has

Published by Copernicus Publications on behalf of the European Geosciences Union. 
been assessed through comparison with radiosonde and radiometer observations (e.g. Revercomb et al., 2003; Van Baelen et al., 2005). Recently, GNSS data have been compared with high-resolution measurements of a Fourier-Transform Infrared Spectrometer (Schneider et al., 2010), an instrument that yields data with a theoretical precision of a few percent, concluding that for IWV over $3.5 \mathrm{~kg} \mathrm{~m}^{-2}$, GNSS retrievals present a similar quality than radiosonde or radiometer observations.

Short and medium-range numerical weather prediction (NWP) models suffer from inadequate observational definition of the three-dimensional moisture field. Ground-based GNSS observations can provide a vertically-integrated value of that field with a good time resolution in all weather conditions, including those with clouds and precipitation, when a good representation of the moisture field is especially important. The zenith total delay (ZTD) is usually the magnitude that is assimilated. Many authors have reported that the assimilation of GNSS observations has a positive impact on the performance of a NWP model (Smith et al., 2007; Poli et al., 2007).

Mazany et al. (2002) and De Haan et al. (2004) can be mentioned among the attempts to use GNSS observations, in combination with other meteorological data, in the nowcasting of precipitation or storm events.

In this paper, we first present a method based on variational assimilation techniques to produce near-real-time maps describing the spatial distribution of IWV. These maps are generated every 15 min using the previous map as the background state. They cover the Iberian Peninsula and the Western Mediterranean region. Finally, the usefulness of the product is assessed in a case of storm activity.

\section{Generation of IWV maps}

The distribution of the atmospheric water is highly variable in the vertical dimension. Since the source is essentially the surface and the principal sink is the precipitation, commonly originated hundreds to thousands of meters above ground, there is an upward decrease of water concentration. The fact is that, on average, nearly half of the total atmospheric water is between sea level and a 1.5-km height and, therefore, the horizontal distribution of water vapour is strongly modulated by the topography. In the Iberian Peninsula, an area of complex orography, the penetration of shallow air masses of maritime origin through passes underneath mountain ranges is a common mechanism of moistening the air of inland regions. This fact makes difficult to build a realistic map of IWV without a high-resolution network of GNSS receivers.

The dependence on height of the parameter to be interpolated is reduced through the introduction of a climatological scaling, which is defined as the division of any IWV value by a local statistical average. The full process of interpolation is performed using the scaled values and the final product is generated after reversing the scaling process. This method requires the previous calculation of IWV averages.

The interpolation process is performed every $15 \mathrm{~min}$, the current temporal resolution of the IWV estimates issued by the Spanish Instituto Geográfico Nacional, the French Institute Géographique National and the Agenzia Spaziale Italiana, the centres that process the GNSS data from the Iberian Peninsula and Western Mediterranean region, our working area. The interpolation is made through a one-dimensional variational assimilation scheme with the previous map as the background state. A similar method, although without scaling the IWV, has been recently presented in De Haan et al. (2009).

\subsection{Generation of climatological maps}

The mean geographical distribution of IWV is computed from the dataset of daily averages at the different stations. Since this dataset usually presents some gaps, the estimation of the mean values and covariance matrix is performed together with the imputation of the missing values using the iterative method based on the maximization-expectation algorithm described in Schneider (2001).

The average values of IWV calculated at the different receiving stations are, then, mapped using a combination of statistic methods and geostatistical techniques of interpolation, following Tellez et al. (2008). First, a multiple regression analysis yields a model accounting for the statistical dependence of the mean values on latitude, longitude and altitude. Then, the residuals, that is, the difference between those averaged values and the prediction of the linear model, are spatially interpolated using an ordinary kriging. The final result is the addition of the map drawn from the model predictions and the map of residuals.

\subsection{The variational assimilation of IWV values}

The analysis of the climatologically scaled IWV values is performed by means of a one-dimensional variational assimilation scheme, that is, through the minimisation of the following cost function:

$$
\begin{aligned}
& J(x)=\frac{1}{2}\left(x-x_{b}\right)^{T} B^{-1}\left(x-x_{b}\right) \\
& +\frac{1}{2}\left(y_{o}-H(x)\right)^{T} R^{-1}\left(y_{o}-H(x)\right)
\end{aligned}
$$

where $B$ and $R$ represent background error and the sum of observation and representativeness error covariances, respectively, $x$ represents the array of scaled IWV values at a grid mesh of a $0.2 \times 0.2$ degree resolution, $x_{b}$ is the array of background values, $y_{o}$ are observations and $H(x)$ is the observation operator.

A key point of the method is an accurate estimation of the covariance matrices. The background-error covariance matrix is empirically built from the difference between 


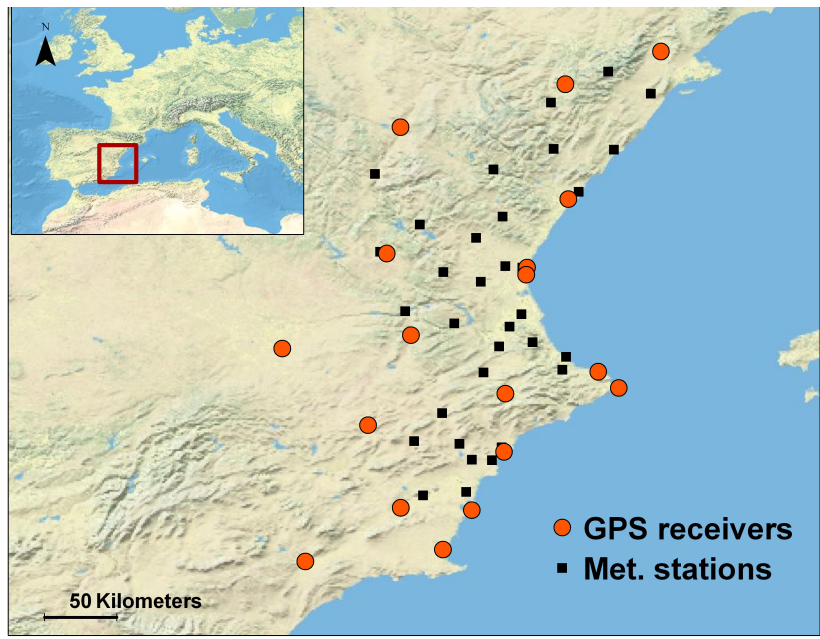

Fig. 1. GNSS receivers and meteorological stations at València region.

successive IWV values for every pair of stations. The values for every station are then fit to a 2-D-Gaussian and, finally, the parameters of the Gaussian surface are interpolated to the grid points. On the other hand, as stated by De Haan et al. (2009), observation errors are correlated as a result of the method used to process the GNSS observations. However, as in the mentioned paper, we assume that these correlations can be neglected. The observation operator maps the state space $(x)$ to the observations using a Gaussian-weighted average of the nearest points. Finally, the minimisation of the cost function is performed through the conjugate gradient method with the Polak-Ribière algorithm (Polak and Ribière, 1969).

\section{A case study: València, 7-8 July 2009}

València region is situated in the mid-Mediterranean front of the Iberian Peninsula (see Fig. 1). It is surrounded to the west by mountain ranges that facilitate the uplift of maritime air and cause not infrequent events of heavy convective rain.

After the passage of a weak cold front throughout the northern part of the Iberian Peninsula, the synoptic situation during the night of 7 July 2009 is dominated by an Atlantic anticyclone and low pressure over the Mediterranean, leading a warm and wet eastern flow to the València region. A trough approaches the Peninsula from the west progressively increasing the column instability. Convective rain and storms are expected, but it is not possible to precisely forecast time and location of occurrence. On 8 July at 01:20 UTC, heavy rain and storm activity start in València city. Convection rapidly moves eastwards, to the sea, but $33.9 \mathrm{~mm}$ of precipitation is recorded in the city weather station, with a peak 10minute intensity of $57.0 \mathrm{~mm} \mathrm{~h}^{-1}$. Other showers are later observed in the rest of the region, but they produce very scarce precipitation (Figs. 2 and 3).

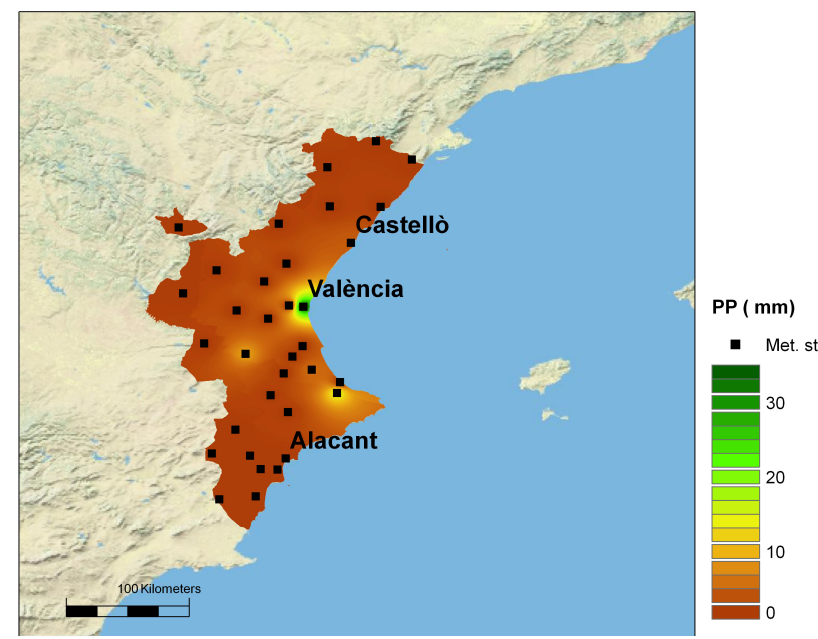

Fig. 2. Rainfall (mm) recorded between 00:00 and 06:00 UTC on 8 July 2009. Black boxes indicate the location of meteorological stations.

In the evening of 7 July, scattered Stratocumuli are observed everywhere in the region. Stratiform clouds are spotted in visible - until sunset - and infrared satellite channels, and reported in manual observations. Nevertheless, there is not any sign of convection in the satellite imagery. The development of a convective cell is not evident until well after midnight, only about half an hour before rain and storm hit the city. Figure 4 shows the first signs of convection on 8 July at 00:45 UTC and Fig. 5 the mature cell moving eastwards at 01:45 UTC. Both figures present the spatial distribution of IWV at their upper-left corner.

At 18:45 UTC 7 July, estimates of IWV in València city are $2-4 \mathrm{~kg} \mathrm{~m}^{-2}$ above those in other coastline stations (Fig. 6). From that time, there is a very fast increase of IWV, about $7 \mathrm{~kg} \mathrm{~m}^{-2}$ in $6 \mathrm{~h}$ (Fig. 3a), while the rise is only $5 \mathrm{~kg} \mathrm{~m}^{-2}$ in Borriana, $52 \mathrm{~km}$ north-northeastwards (Fig. 3b) and a nearly negligible $1 \mathrm{~kg} \mathrm{~m}^{-2}$ in Alacant, $127 \mathrm{~km}$ southsouthwestwards (Fig. 3c). It results in a progressive growing of the peak around the city. On 8 July at 00:45 UTC, when the first convective clouds can be distinguished in the satellite images, the IWV in València city is $10 \mathrm{~kg} \mathrm{~m}^{-2}$ higher than in the surroundings (Fig. 7). Several minutes later, there is heavy rain and storm activity over the city. The release of precipitation and the displacement of the main convective area produce a rapid decay in the IWV values. In this case, the GNSS product allows early identification of an area with a fast increase of IWV, that is, an area of moisture convergence, where convection can be triggered in a situation of conditional instability.

After a year of experience in the use of the product, different cases have been found, in which convection is focalised in areas with higher IWV values than in the surroundings, after a period of fast increase of the parameter. In those cases, IWV maps represent an excellent tool to the forecaster. 
a)

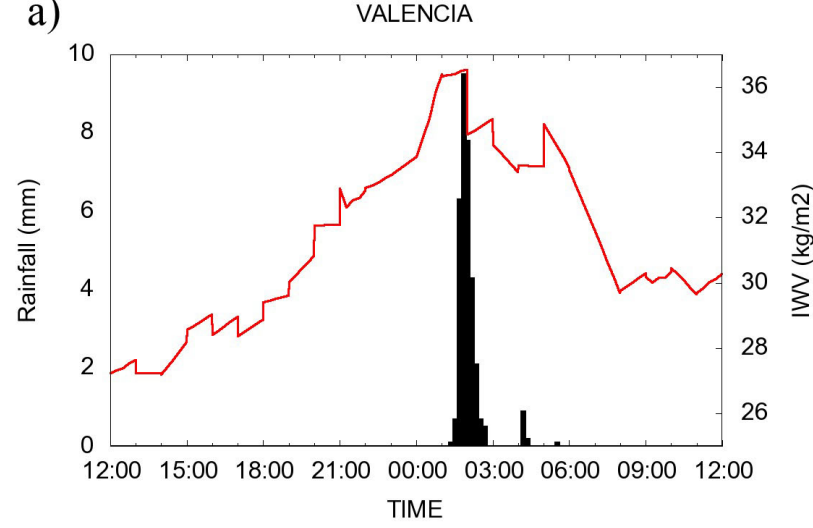

b)

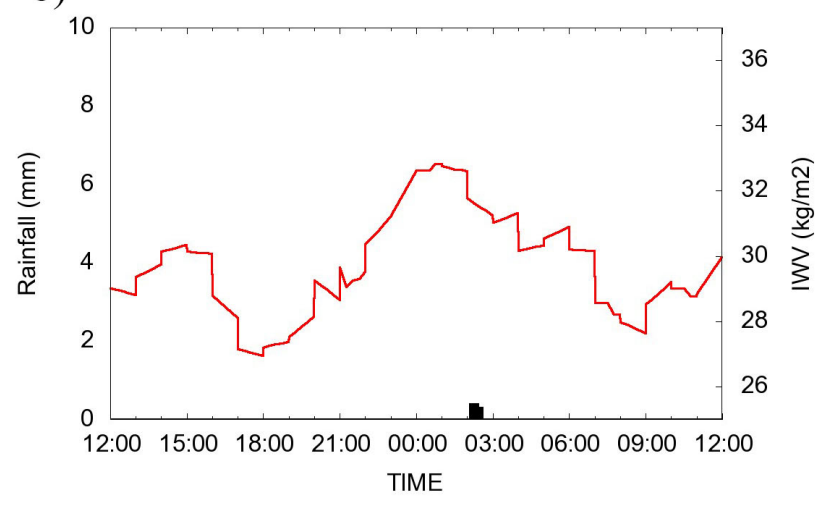

c)

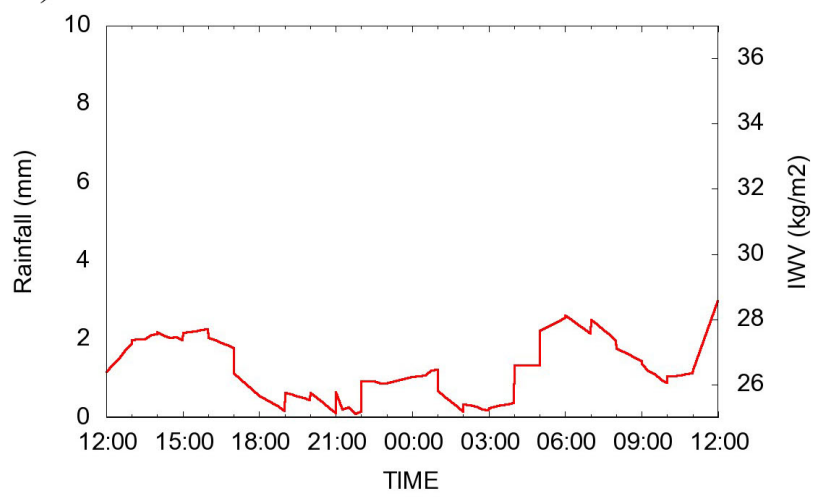

Fig. 3. Rainfall (in black) and integrated water vapour (in red) observed from 12:00 UTC 7 July 2009 to 12:00 UTC 8 July 2009 in València (a), Borriana / Castelló (b) and Alacant (c).

Nevertheless, it is necessary to point out the existence of false-alarm cases, where either the moisture convergence is too weak or the stratification is too stable to allow storm development. In addition, the period of IWV increase prior to the convection usually ranges between tens of minutes and several hours and, thus, it is not always longer than the current latency of the product. Finally, IWV maps seem to be of less interest once the convection is developed and other

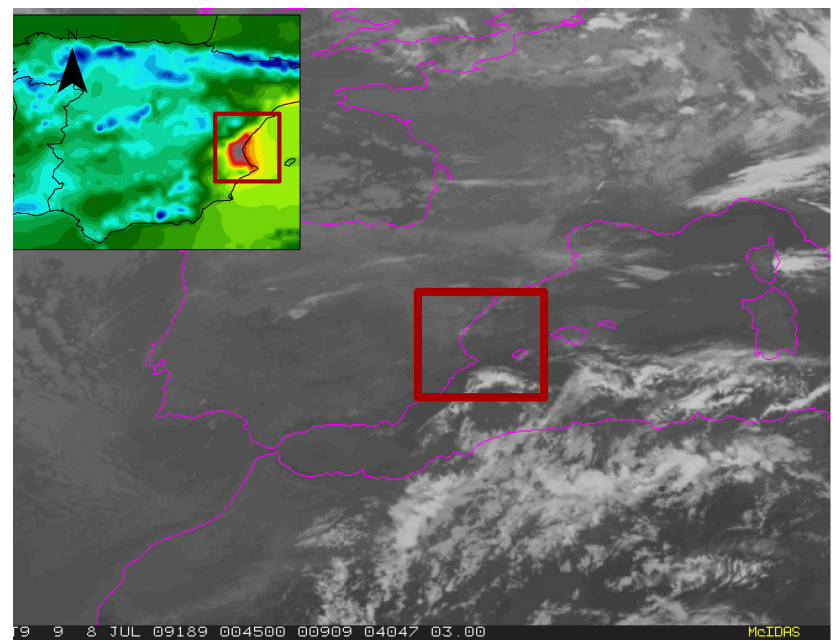

Fig. 4. METEOSAT image (channel 9, centred at $10.8 \mu \mathrm{m}$ ) and spatial distribution of integrated water vapour (upper-left corner) for 8 July 2009 at 00:45 UTC.

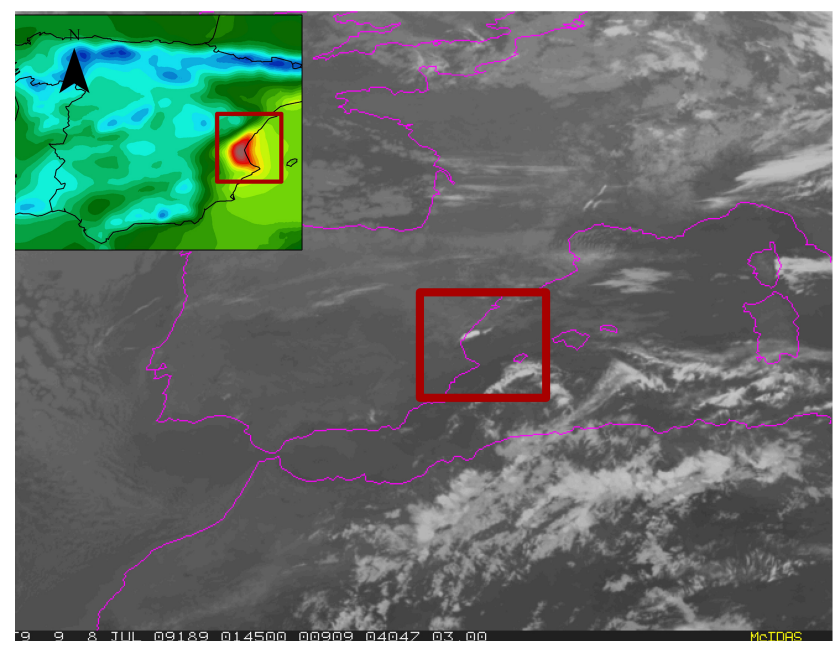

Fig. 5. METEOSAT image (channel 9, centred at $10.8 \mu \mathrm{m}$ ) and spatial distribution of integrated water vapour (upper-left corner) for 8 July 2009 at $01: 45$ UTC.

remote-sensing techniques yield more useful information to nowcasting.

\section{Conclusions and future work}

GNSS networks have proven to be a relatively cheap and reliable all-weather system to monitor atmospheric humidity with a good spatial and temporal resolution. The close relationship found in numerous cases between convective precipitation and a fast increase of IWV suggests the possible application of GNSS-derived IWV in operational nowcasting. 


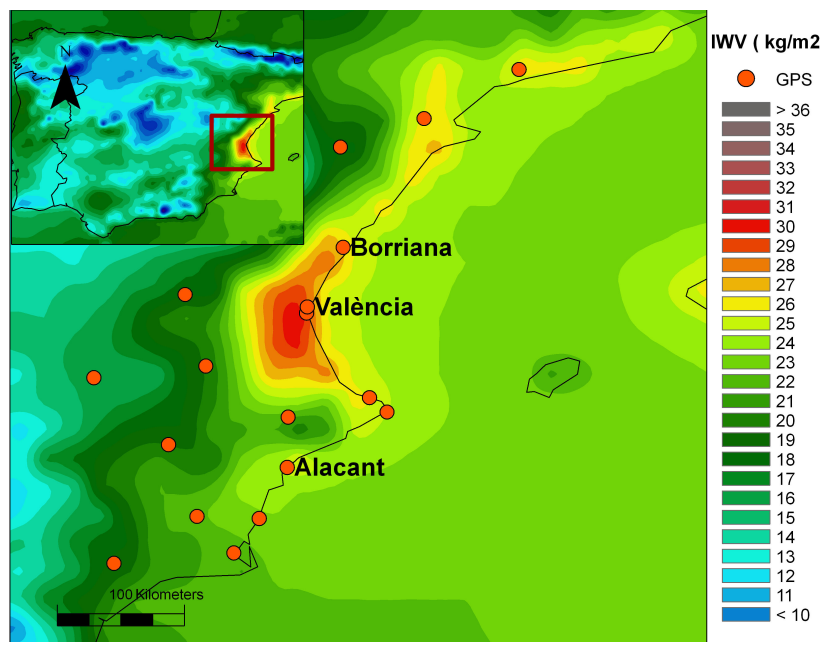

Fig. 6. Estimation of integrated water vapour $\left(\mathrm{kg} \mathrm{m}^{-2}\right)$ on 7 July at 18:45 UTC. Red circles indicate the location of GNSS receivers.

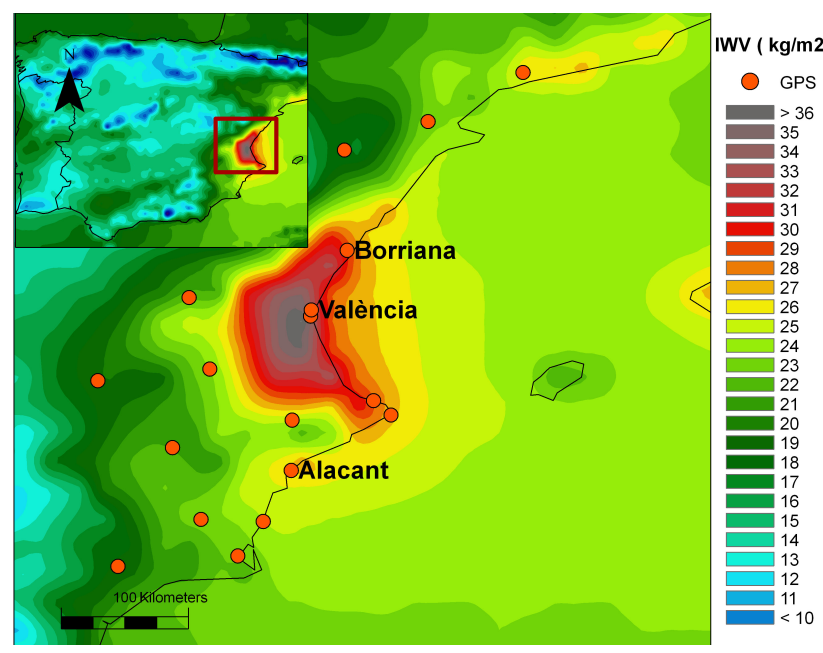

Fig. 7. Estimation of integrated water vapour $\left(\mathrm{kg} \mathrm{m}^{-2}\right)$ on 8 July at 00:45 UTC.

This paper describes the production of maps presenting the geographical distribution of IWV in the western part of the Mediterranean basin. This product constitutes a promising tool for the operational forecaster. It displays areas with strong moisture convergence and, therefore, potential convection triggering, causing alarm bells to ring long before any sign appears in other remote sensing systems.

The use of GNSS measurements in meteorology requires a relatively complex data process. At present, most IWV estimates are available between 45 and $90 \mathrm{~min}$ after its nominal time. This latency can be acceptable for NWP, but is excessive for nowcasting applications. A shorter latency should arrive together with a harmonisation of the processing methods. The application of different methods to estimate IWV from GNSS observations entails different spatial and time correlations among data that not always can be taken into account in the assimilation process.

The meteorological application of GNSS observations requires a very precise calculation of the distance between receiver and satellites. The background motion makes it unfeasible over the sea. It would force to complement GNSS with other data sources (i.e. retrievals from satellite imagery).

Acknowledgements. The authors thank the GPS data providers, especially those in the EUREF Permanent Network (EPN), for giving access to their data and products. They also thank the Spanish Instituto Geográfico Nacional, the French Institut Géographique National and the Agenzia Spaziale Italiana, which carry with the data processing in the area of interest.

Edited by: A. Mugnai

Reviewed by: one anonymous referee

\section{References}

Bevis, M., Businger, S., Herring, T. A., Rocken, C., Anthes, R. A., and Ware, R. H.: G.P.S. meteorology: remote sensing of atmospheric water vapour using the Global Positioning System, J. Geophys. Res., 97, 15787-15801, 1992.

Bevis, M., Businger, S., Chiswell, S., Herirng, T. A., Anthes, R. A., Rockmen, C., and Ware, R. H.: GPS meteorology: Mapping zenith wet delays onto perceptible water, J. Appl. Meteor., 33, 379-386, 1994.

Brunner, F. K. and Gu, M.: An improved model for the dual frequency ionospheric correction of GPS observations, Manusc. Geod., 16, 205-214, 1991.

De Haan S., Barlag, S. J. M., Baltink, H. K., and Debie, F.: Synergetic use of GPS water vapor and Meteosat images for synoptic weather forecasting, J. Appl. Meteor., 43, 514-518, 2004.

De Haan, S., Holleman, I., and Holtslag, A. A. M.: Real-time water vapor maps from a GPS surface network: construction, validation and applications, J. Appl. Meteor. Climatol., 48, 1302-1316, 2009.

Mazany R. A., Businger, S., Gutman, S. I., and Roeder, W.: A lightning prediction index that utilizes GPS integrated precipitable water vapor, Weather Forecast., 17, 1034-1047, 2002.

Melsheimer, C., and Heygster, G.: Improved retrieval of total water vapor over polar regions from AMSU-B microwave radiometer data, IEEE Trans. Geosci. Remote Sens. 46, 2307-2322, 2008.

Polak, E. and Ribière, G.: Note sur la convergence de directions conjugées, Rev. Fr. Inform. Rech. Oper., 16, 35-43, 1969.

Poli, P., Moll, P., Rabier, F., Desroziers, G., Chapnik, B., Berre, L., Healy, S. B., Andersson, E., and El Guelai, F.-Z.: Forecast impact studies of zenith total delay data from European near realtime GPS stations in Météo France 4DVAR, J. Geophys. Res., 112, D06114, doi:10.1029/2006JD007430, 2007.

Revercomb, H. E., Turner, D. D., Tobin, D. C., Knuteson, R. O., Feltz, W. F., Barnard, J., Bösenberg, J., Clough, S., Cook, D., Ferrare, R., Goldsmith, J., Gutman, S., Halthore, R., Lesht, B., Liljegren, J., Linné, H., Michalsky, J., Morris, V., Porch, W., Richardson, S., Schmid, B., Splitt, M., van Hove, T., Westwater, E., and Whiteman, D.: The ARM program's water vapor intensive observation periods: Overview, initial accomplishments and future challenges, B. Am. Meteorol. Soc., 84, 217-236, 2003. 
Rocken, C., Van Hove, T., Johnson, J., Solheim, F., Ware, R. H., Bevis, M., Businger, S., and Chiswell, S.: GPS/STORM - GPS Sensing of Atmospheric Water Vapor for Meteorology, J. Atmos. Ocean. Tech., 12, 468-478, 1995.

Schneider, T.: Analysis of incomplete climate data: Estimation of mean values and covariance matrices and imputation of missing values, J. Climate, 14, 853-871, 2001.

Schneider, M., Romero, P. M., Hase, F., Blumenstock, T., Cuevas, E., and Ramos, R.: Continuous quality assessment of atmospheric water vapour measurement techniques: FTIR, Cimel, MFRSR, GPS, and Vaisala RS92, Atmos. Meas. Tech., 3, 323338, doi:10.5194/amt-3-323-2010, 2010.
Smith, T. L., Gutman, S. I., and Sahm, S. R.; Forecast impact from assimilation of GPS IPW observations into the Rapid Update Cycle, Mon. Weather Rev., 135, 2914-2930, 2007.

Spilker, J. J.: GPS signal structure and performance characteristics, Global Positioning System, vol. 1, The Institute of Navigation, Washington, DC, 1980.

Téllez, B., Cernocky, T., and Terradellas, E.: Calculation of climatic reference values and its use for automatic outlier detection in meteorological datasets, Adv. Sci. Res., 2, 1-4, 2008.

Van Baelen, J., Aubagnac, J.-P., and Dabas, A.: Comparison of Near-Real Time Estimates of Integrated Water Vapor Derived with GPS, Radiosonde, and Microwave Radiometer, J. Atmos. Ocean. Tech., 22, 201-210, 2005. 